\title{
Controle genético da resistência à mancha-de-Phaeosphaeria em milho
}

\author{
Genetic control of resistance to Phaeosphaeria leaf spot in maize
}

\author{
Maria Teresa Gomes Lopes ${ }^{\mathrm{I}}$ Ricardo Lopes ${ }^{\mathrm{II}}$ Kátia Regiane Brunelli ${ }^{\mathrm{II}}$ \\ Herberte Pereira da Silva ${ }^{\mathrm{IV}}$ Rodrigo Rodrigues Matiello ${ }^{\mathrm{V}}$ \\ Luis Eduardo Aranha Camargo ${ }^{\mathrm{VI}}$
}

\section{RESUMO}

A mancha-de-Phaeosphaeria, de ampla ocorrência no Brasil, tem causado expressiva redução na produtividade da cultura do milho no pais. Por isso, o desenvolvimento de hibridos resistentes à doença é um dos principais objetivos dos programas de melhoramento genético da cultura. Informações sobre o controle genético da resistência à doença são necessárias para que os programas de melhoramento sejam eficientes. O objetivo deste estudo foi determinar o controle genético da resistência à mancha-dePhaeosphaeria em milho a partir da avaliação das médias de gerações oriundas de dois cruzamentos entre linhagens resistentes (DAS95 ou DAS72) com uma suscetivel (DAS21), sob condições de infecção natural da doença. Os ensaios foram conduzidos em Indianópolis (MG), em duas épocas de semeadura, outubro e novembro de 2000. Foi utilizado o delineamento experimental blocos ao acaso com três repetições. A avaliação para resistência foi realizada 30 dias após o florescimento com auxilio de uma escala diagramática de porcentagem de tecido foliar total da planta afetado pela doença. As médias da severidade da doença dos genitores e das gerações $F_{1}, F_{2}, R C P_{1}$ e RCP foram analisadas segundo o modelo de MATHER \& JINKS (1971). A variação genética devida a efeitos aditivos foi de 73 a 84\%, enquanto, devido aos efeitos dominantes, foi de 13 a 23\%. Foi evidenciada a predominância dos efeitos gênicos aditivos sobre dominantes em ambas as populações estudadas. Os valores da herdabilidade foram altos, variando de 61 a $88 \%$. Os resultados indicaram condições favoráveis ao melhoramento genético visando àresistência à mancha-de-Phaeospheria nas populações estudadas.
Palavras-chave: Phaeosphaeria maydis, resistência genética, análise de média de gerações, melhoramento genético.

\section{ABSTRACT}

The Phaeosphaeria leaf spot, of ample occurrence in Brazil, has been causing an expressive reduction in the corn yield in the country. Thus, the development of resistant hybrids to this disease is one of the main objectives of corn breeding programs. Information about the genetic control of resistance to the disease is necessary so that the programs can be efficient. The main goal of this study was to determine the genetic control of resistance to the Phaeosphaeria leaf spot in maize through the assessment of the generation means from two crossing between a resistant inbred line (DAS95 or DAS72) with a susceptible line (DAS21) under natural infection conditions of the disease. The experiment was carried out in Indianópolis $(M G)$ in two sowen dates, October and November, 2000. The randomized blocks design with three repetitions was utilized. The evaluation to resistance was performed thirty days after the flowering using a diagrammatic scale of percentage of the total foliar tissue of the plant affected by the disease. Disease severity means of parental lines and generations $F_{1}, F_{2}, R C P_{1}$ and $R C P$, were analysed according to the model by MATHER \& JINKS (1971). Genetic variation due to additive effects varied from $73 \%$ to $84 \%$ whilst dominant effects ranged from $13 \%$ to $23 \%$. In both studied population, the predominance of gene additive over dominant effects was evidented. The inheritance values were high, varying from $61 \%$ to $88 \%$. These results indicate favourable conditions to develop new resistance lines to Phaeosphaeria leaf spot with the studied populations.

\footnotetext{
IFaculdade de Ciências Agrárias, Universidade Federal do Amazonas (UFAM). Av. Rodrigo Octávio Jordão Ramos, n. 3000, 69077000, Manaus, AM, Brasil. E-mail: mtglopes@ufam.edu.br. Autor para correspondência.

IIEmbrapa Amazônia Ocidental, Manaus, AM, Brasil.

IIISakata Sementes, Bragança Paulista, SP, Brasil.

${ }^{\text {IV }}$ Sementes Dow Agrosciences Ltda, Indianópolis, MG, Brasil.

v Departamento de Fitotecnia e Fitossanidade, Universidade Estadual de Ponta Grossa (UEPG), PR, Brasil.

${ }^{v I}$ Departamento de Fitopatologia, Entomologia e Zoologia Agrícola, Escola Superior de Agricultura Luiz de Queiroz, Universidade de São Paulo (ESALQ/USP). São Paulo, Brasil.
} 
Key words: Phaeosphaeria maydis, disease resistance, generation mean analysis, plant breeding.

\section{INTRODUÇÃO}

A mancha-de-Phaeosphaeria, ou pinta branca, é considerada, no Brasil, a principal doença do milho, tanto pelos prejuízos que tem causado às cultivares suscetíveis, como pela sua ampla distribuição (SILVA, 2002), sendo encontrada em todas as regiões brasileiras onde o milho é cultivado (FERNANDES \& OLIVEIRA, 1997).

A mancha-de-Phaeosphaeria é causada pelo fungo Phaeosphaeria maydis (P. Henn.) Rane, Payak e Renfro (sinônimo Sphaerulina maydis), cujo estádio anamórfico é Phillosticta sp. (REIS \& CASA, 1996; FERNANDES \& OLIVEIRA, 1997). Os sintomas apresentam-se na forma de lesões foliares em número variável, circulares a elípticas, caracterizam-se, no início, por lesões aquosas verde-claro que vão evoluindo para acinzentadas a necróticas (FERNANDES \& OLIVEIRA, 1997). Geralmente, os sintomas aparecem primeiro nas folhas inferiores, progredindo rapidamente para o ápice da planta (FERNANDES \& OLIVEIRA, 1997; PEGORARO et al., 2002).

A avaliação da natureza e magnitude dos efeitos gênicos que controlam um determinado caráter tem grande importância no processo de seleção e predição do comportamento de gerações híbridas e populações segregantes. A estimativa das proporções atribuídas a efeitos gênicos aditivos, dominantes e epistáticos é fundamental, uma vez que a importância relativa desses fatores norteia os programas de melhoramento (CRUZ \& REGAZZI, 1997)

Embora a mancha-de-Phaeosphaeria seja de reconhecida importância, é recente a atenção à obtenção de informações genéticas quanto à resistência a esta doença. A característica é descrita como quantitativa, sendo a ação gênica aditiva de maior importância na herança do caráter quando comparada à dominante (LIMA et al., 1998; PATERNIANI et al., 1998; CARSON, 2001; PEGORARO et al., 2002; SILVA, 2002). A resistência à mancha-de-Phaeosohaeria tem sido relatada ainda como caráter que apresenta alta herdabilidade(CARSON, 2001; PEGORARO et al., 2002; SILVA, 2002).

O objetivo deste trabalho foi estudar a natureza e a magnitude dos efeitos gênicos da resistência à mancha-de-Phaeosphaeria, em duas populações de milho.

\section{MATERIAL E MÉTODOS}

Neste trabalho, foram analisadas as linhagens DAS21, DAS95 e DAS72, usadas no programa de melhoramento genético e produção de sementes de milho da empresa Sementes DowAgroSciences Ltda, e as gerações $F_{1}, F_{2}, R C P_{1}$ e $\mathrm{RCP}_{2}$, derivadas dos cruzamentos de DAS95 x DAS21 e de DAS72 x DAS21. As linhagens genitoras foram obtidas a partir de compostos tropicais, sendo DAS21 suscetível e DAS95 e DAS72 resistentes à mancha-dePhaeosphaeria.

Os experimentos foram instalados na estação experimental da empresa Sementes DowAgroSciences Ltda, em Indianópolis, MG (latitude $18^{\circ} 55^{\prime} \mathrm{S}$, longitude $47^{\circ} 51^{\prime} \mathrm{W}$ e altitude de $975 \mathrm{~m}$ ). Foram realizados dois experimentos em duas épocas de plantio diferentes. A semeadura do primeiro e do segundo ensaio foi realizada em outubro e novembro de 2000, respectivamente. A região apresenta umidade relativa do ar média de $68 \%$, precipitação pluvial média de 1490mm anuais, com maior concentração nos meses de novembro a março, o que favoreceu o desenvolvimento da doença durante os experimentos (outubro a março). Além disso, a área utilizada é continuamente cultivada com milho, o que garantiu a fonte de inóculo. Foi realizada adubação de plantio com $500 \mathrm{~kg} \mathrm{ha}^{-1}$ de 5-2020 e de cobertura com $200 \mathrm{~kg} \mathrm{ha}^{-1}$ de uréia, dividida em duas aplicações, aos 25 e 50 dias após a germinação.

Os experimentos foram conduzidos no delineamento experimental blocos casualizados com três repetições, sendo os tratamentos constituídos pelas gerações. Cada parcela foi representada por uma fileira de $5 \mathrm{~m}$ para as gerações parentais $\left(\mathrm{P}_{1}\right.$ e $\left.\mathrm{P}_{2}\right)$ e $\mathrm{F}_{1}$, duas fileiras de $5 \mathrm{~m}$ para as gerações $\mathrm{RCP}_{1}$ e $\mathrm{RCP}_{2} \mathrm{e}$ quatro fileiras de $5 \mathrm{~m}$ para a geração $\mathrm{F}_{2}$, sendo cada fileira constituída de 25 plantas, com espaçamento de $0,20 \mathrm{~m}$ entre plantas e $0,80 \mathrm{~m}$ entre fileiras. Como bordadura, utilizou-se quatro fileiras de um híbrido altamente suscetível à doença (DAS8420). Os experimentos foram realizados com incidência natural do patógeno.

A avaliação da severidade da doença foi feita por dois avaliadores por meio de estimativa visual da área foliar afetada pela doença com auxílio da escala diagramática variando de 1 a 9 , de acordo com a porcentagem da área foliar total da planta afetada (sendo $1=0 \%$; $2=1 \%$; $3>1 \%$ e $\leq 10 \% ; 4>10 \%$ e $\leq 20 \%$; $5>$ $20 \%$ e $\leq 30 \%$; $6>30 \%$ e $\leq 40 \%$; $7>40 \%$ e $\leq 60 \%$; $8>$ $60 \%$ e $\leq 80 \%$; $9>80 \%$ ), sendo 1 altamente resistente, 2 e 3 resistentes, 4 medianamente resistente, 5 e 6 medianamente suscetível, 7 e 8 suscetível e 9 altamente suscetível (AGROCERES, 1996). A avaliação para 
resistência à mancha-de-Phaeosphaeria foi realizada aos 30 dias após o florescimento, por ser indicada por LOPES (2003) como a mais prática e usual em programas de melhoramento e apresentar grande correlação (99\%) com a AUDPC (área abaixo da curva de progresso da doença). Nas análises de variância e de médias de gerações, foi considerada a média entre as notas dos dois avaliadores, visando assim a diminuir-se o erro experimental inerente à avaliação visual.

A natureza e a magnitude dos efeitos gênicos envolvidos no controle genético da resistência à mancha-de-Phaeosphaeria foram estimados por meio da análise individual das médias das gerações $P_{1}$ (DAS72 ou DAS95), $\mathrm{P}_{2}$ (DAS21) e as respectivas gerações: $F_{1}, F_{2}, R C P_{1}$ e $R_{2} P_{2}$, segundo o modelo de MATHER \& JINKS (1971) $\mathrm{Y}_{\mathrm{k}}=\mathrm{m}+\mathrm{w}_{1} \mathrm{a}+\mathrm{w}_{2} \mathrm{~d}+\mathrm{q}_{\mathrm{k}}$, no qual Y é a média da geração k, $m$ é a média geral, a representa o efeito aditivo, d o efeito gênico dominante, $\mathrm{w}_{1}$ e $\mathrm{w}_{2}$ as relativas contribuições destes efeitos para cada média da geração e qk os desvios do modelo para cada família. As estimativas dos parâmetros $\mu, a$ e $d$ do modelo foram obtidas pela resolução da equação $\mathrm{b}=\left(\mathrm{X}^{\prime} \mathrm{X}\right)^{-1} \mathrm{X}^{\prime} \mathrm{Y}$ do sistema $\left(\mathrm{y}=\mathrm{X}^{\prime} \mathrm{b}\right)$ de MATHER \& JINKS (1971), sendo Y o vetor das médias observadas das gerações para cada família, $\mathrm{X}$ a matriz dos coeficientes e b o vetor dos parâmetros. A análise de variância individual para a obtenção das médias de gerações foi realizada pelo método dos quadrados mínimos (MIRANDA FILHO, 1991).

O estudo dos parâmetros propostos por MATHER \& JINKS (1971) foi realizado também através da análise conjunta, considerando-se as médias das gerações $\mathrm{P}_{1}$ (DAS72 ou DAS95), $\mathrm{P}_{2}$ (DAS21) e as respectivas gerações: $F_{1}, F_{2}, R_{1}$ e $R_{C P}$ de cada ambiente (L). Foi utilizado o modelo: $\mathrm{Y}_{\mathrm{kj}}=\mathrm{m}+\mathrm{w}_{1 \mathrm{kj}} \mathrm{a}+$ $w_{2 k j} d+l j+w_{1 k_{j}} a l+w_{2 k j} d l+\theta_{k j}$, no qual Y é a média da geração $\mathrm{k}$ no ambiente j para uma determinada família, $\mathrm{m}$ é a média geral, a representa o efeito aditivo, $\mathrm{d}$ o efeito gênico dominante, $\mathrm{w}_{1}$ e $\mathrm{w}_{2}$ as relativas contribuições destes efeitos para cada média da geração, l o efeito de ambiente, al interação do efeito aditivo com ambiente, dl interação do efeito dominante com ambiente e $\theta_{\mathrm{kj}}$ os desvios do modelo. A análise de variância conjunta para a obtenção das médias de gerações foi realizada pelo método dos quadrados minímos conforme REGINATO NETO (1998).

Estimativas da herdabilidade no sentido amplo foram obtidas pela fórmula $\left(\sigma_{\mathrm{F} 2}^{2}-\sigma_{\mathrm{e}}^{2}\right) / \sigma_{\mathrm{F} 2}^{2}$, na qual $\sigma_{\text {F2 }}^{2}$ é a variância fenotípica dos indivíduos na geração $\mathrm{F}_{2}$ e $\sigma_{\mathrm{e}}^{2}$ é a variância ambiental entre indivíduos do mesmo genótipo, estimada através do agrupamento da soma de quadrados e dos graus de liberdade das linhagens parentais e da geração $F_{1}$. A determinação do número de genes ou blocos gênicos segregantes (K) nos cruzamentos foi feita a partir da fórmula de Castle - Wright (CASTLE, 1921; WRIGHT, 1921), sendo $\mathrm{K}=\mathrm{D}^{2 / 8}\left(\sigma_{\mathrm{F} 2}-\sigma_{\mathrm{F} 1}\right)$, na qual $\mathrm{D}$ é a diferença entre as médias das linhagens genitoras, $\sigma_{\mathrm{F} 1}$ e $\sigma_{\mathrm{F} 2}$ os desviospadrão da média das gerações $\mathrm{F}_{1}$ e $\mathrm{F}_{2}$, respectivamente.

\section{RESULTADOS E DISCUSSÃO}

A distribuição das freqüências da severidade da doença nas gerações $\mathrm{F}_{2}, \mathrm{RCP}_{1}$ e $\mathrm{RCP}_{2}$, nos dois experimentos, é representada de maneira gráfica na figura 1. Tal distribuição é uma simplificação do agrupamento das médias usando-se os limites de classificação da escala diagramática. A distribuição comportou-se de maneira não-normal, típica de características em que poucos genes estão envolvidos. Foi verificada a presença de segregação transgressiva de plantas $\mathrm{F}_{2}$, indicando a possibilidade da linhagem DAS21(suscetível) apresentar gene(s) de resistência diferente(s) dos genes de resistência das linhagens DAS95 e DAS72 (resistentes). Esse fato corrobora os resultados de mapeamento utilizando marcadores moleculares realizado por LOPES (2003), em uma população de plantas $F_{2}$ do cruzamento DAS95 X DAS21, que indicaram a presença de gene(s) de resistência no genitor suscetível DAS21. Assim, pela combinação dos genitores DAS21, DAS95 e DAS72, podem ser obtidas linhagens que concentrem maior número de genes de resistência do que os mesmos.

Os resultados da avaliação fenotípica foram submetidos à análise de variância individual e conjunta (Tabelas 1 e 2). A homogeneidade das variâncias dos experimentos foi verificada a partir da razão entre o maior e o menor quadrado médio do resíduo. Sendo esta relação inferior a 7, as variâncias residuais dos experimentos foram consideradas homogêneas (GOMES, 1990).

Nas análises de variância individual e conjunta dos experimentos, constatou-se efeito significativo de tratamentos $(\mathrm{P}<0,05)$, indicando que as linhagens genitoras das gerações segregantes são contrastantes para resistência à doença (Tabelas $1 \mathrm{e}$ 2). Na análise conjunta, verificou-se efeito significativo de época de realização dos experimentos decorrente de alterações nas médias das gerações do primeiro e do segundo experimento. Também foi verificado efeito significativo para a interação genótipo x época de semeadura dos experimentos, indicando resposta diferencial das gerações em função da época. A pressão do inóculo sobre a segunda época de plantio foi superior à primeira, em função da multiplicação do patógeno na área, o que pode justificar o aumento das 


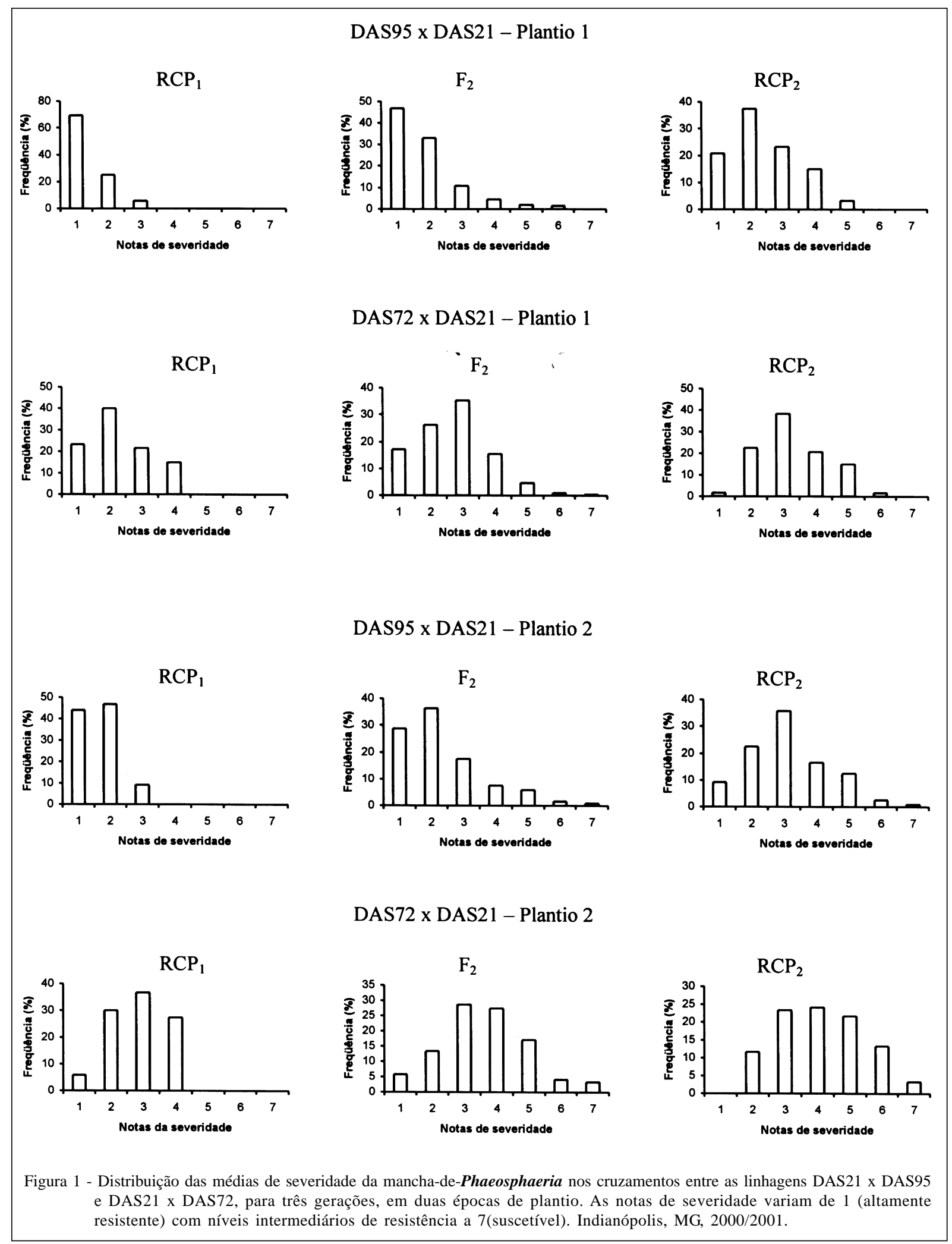

Ciência Rural, v.37, n.3, mai-jun, 2007. 
Tabela 1 - Resumo da análise de variância individual e médias das gerações da avaliação da severidade da mancha-de-Phaeosphaeria nos experimentos. Indianópolis, MG, 2000/2001.

\begin{tabular}{|c|c|c|c|c|c|}
\hline \multirow{2}{*}{ Fonte de variação } & \multirow{2}{*}{ GL } & \multicolumn{4}{|c|}{ QM } \\
\hline & & \multicolumn{2}{|c|}{ Experimento 1} & \multicolumn{2}{|c|}{ Experimento 2} \\
\hline Bloco & 2 & \multicolumn{2}{|c|}{0,1239} & \multicolumn{2}{|c|}{0,0075} \\
\hline Tratamento & 10 & \multicolumn{2}{|c|}{$2,8444^{*}$} & \multicolumn{2}{|c|}{$5,8801^{*}$} \\
\hline \multirow[t]{2}{*}{ Resíduo } & 20 & \multicolumn{2}{|c|}{0,0705} & \multicolumn{2}{|c|}{0,5771} \\
\hline & & DAS21 x DAS95 & DAS21 x DAS72 & DAS21 x DAS95 & DAS21 x DAS72 \\
\hline Média P1 & & 4,513 & 4,513 & 5,970 & 5,970 \\
\hline Média P2 & & 1,108 & 2,109 & 1,123 & 2,762 \\
\hline Média F1 & & 1,299 & 2,387 & 1,426 & 3,277 \\
\hline Média F2 & & 1,833 & 2,683 & 2,298 & 3,736 \\
\hline Média RCP1 & & 2,211 & 3,233 & 3,168 & 4,327 \\
\hline Média RCP2 & & 1,395 & 2,531 & 1,650 & 3,070 \\
\hline $\mathrm{CV}(\%)$ & & \multicolumn{2}{|c|}{11,54} & \multicolumn{2}{|c|}{8,05} \\
\hline
\end{tabular}

* significativo a 5\% de probabilidade pelo teste $\mathrm{F}$.

notas médias de severidade da doença na segunda época de plantio (Tabela 1).

A linhagem DAS95 apresentou maior resistência à doença (médias 1,10 e 1,12, experimentos 1 e 2, respectivamente), seguida pela linhagem DAS72 (médias 2,10 e 2,76, experimentos 1 e 2, respectivamente), sendo a linhagem DAS21 a mais suscetível (médias 4,51 e 5,97, experimentos 1 e 2 , respectivamente). O comportamento dessas linhagens quanto à resistência à mancha-de-Phaeosphaeria foi semelhante ao relatado

Tabela 2 - Resumo da análise de variância conjunta e médias das gerações da avaliação da severidade da mancha-dePhaeosphaeria. Indianópolis, 2000/2001.

\begin{tabular}{|c|c|c|c|}
\hline Fonte de variação & GL & \multicolumn{2}{|c|}{ QM } \\
\hline Bloco & 2 & \multicolumn{2}{|c|}{0,0664} \\
\hline Bloco/Época & 4 & \multicolumn{2}{|c|}{0,0657} \\
\hline Tratamento & 10 & \multicolumn{2}{|c|}{$8,420 *$} \\
\hline Época & 1 & \multicolumn{2}{|c|}{$7,6751^{*}$} \\
\hline Tratamento x época & 10 & \multicolumn{2}{|c|}{$0,3042 *$} \\
\hline \multirow[t]{2}{*}{ Resíduo } & 40 & \multicolumn{2}{|c|}{0,0641} \\
\hline & & DAS21 x DAS95 & DAS21 x DAS72 \\
\hline Média P1 & & 5.242 & 5.242 \\
\hline Média P2 & & 1.116 & 2.435 \\
\hline Média F1 & & 1.362 & 2.832 \\
\hline Média F2 & & 2.066 & 3.210 \\
\hline Média RCP1 & & 2.690 & 3.780 \\
\hline Média RCP2 & & 1.522 & 2.800 \\
\hline CV(\%) & & \multicolumn{2}{|c|}{9,59} \\
\hline
\end{tabular}

* significativo a 5\% de probabilidade pelo teste F. por SILVA (2002). Os híbridos $\left(\mathrm{F}_{1}\right)$ resultantes dos dois cruzamentos apresentaram médias próximas à linhagem resistente em cada cruzamento. As gerações $F_{2}$ apresentaram médias intermediárias aos genitores e as médias dos retrocruzamentos tenderam a aproximar-se das médias das linhagens utilizadas como genitor recorrente.

As estimativas dos parâmetros genéticos com base nas médias das gerações foram obtidas usando o modelo reduzido composto pelos parâmetros $m, a$ e $d$ e realizada análise de variância. Tanto na análise de variância individual (Tabela 3), como na conjunta (Tabela 4), os efeitos gênicos aditivos foram mais importantes na determinação do caráter, com participação bem inferior dos efeitos dominantes nas duas populações estudadas. Nas análises individuais, os efeitos gênicos aditivos representaram 74,99 e $84,74 \%$ da variação genética total. Essas proporções foram bem superiores às dos efeitos gênicos dominantes, que variaram de 12,86 a 23,30\% e também às dos desvios do modelo, que variaram de 0,74 a 3,12\%. Na análise conjunta a proporção correspondente aos efeitos aditivos foi $72,83 \%$ da variação total no cruzamento DAS95 x DAS21 e 73,95\% no cruzamento DAS72 x DAS21. A variação devida à dominância foi de 20,52 e 12,83\% nos respectivos cruzamentos. A variância aditiva pode ser definida como uma relação linear entre os valores genotípicos dos indivíduos de uma população e o número de alelos favoráveis que 
Tabela 3 - Resumo da análise de variância da avaliação da severidade da mancha-de-Phaeosphaeria de seis gerações dos cruzamentos (DAS21xDAS95 e DAS21xDAS72) e porcentagens da variação explicada pelos efeitos gênicos aditivos dominantes e pelo desvio do modelo aditivo dominante, de dois experimentos no ano agrícola de 2000/2001.

\begin{tabular}{|c|c|c|c|c|c|c|c|c|c|c|c|c|c|}
\hline \multirow{3}{*}{$\begin{array}{l}\text { Fonte de } \\
\text { Variação }\end{array}$} & \multirow{3}{*}{ GL } & \multicolumn{6}{|c|}{ DAS95 x DAS21 } & \multicolumn{6}{|c|}{ DAS72 x DAS21 } \\
\hline & & \multicolumn{3}{|c|}{ Experimento 1} & \multicolumn{3}{|c|}{ Experimento 2} & \multicolumn{3}{|c|}{ Experimento 1} & \multicolumn{3}{|c|}{ Experimento 2} \\
\hline & & $\mathrm{QM}$ & & $\%$ & $\mathrm{QM}$ & & $\%$ & $\mathrm{QM}$ & & $\%$ & $\mathrm{QM}$ & & $\%$ \\
\hline Total & 6 & & & & & & & & & & & & \\
\hline Parâmetros & 3 & & & & & & & & & & & & \\
\hline Aditivo & 1 & 5,817 & $*$ & 74,99 & 12,570 & $*$ & 78,58 & 3,037 & $*$ & 82,07 & 5,888 & $*$ & 84,00 \\
\hline Dominante & 1 & 1,807 & $*$ & 23,30 & 3,310 & $*$ & 20,68 & 0,621 & $*$ & 16,77 & 0,901 & ns & 12,86 \\
\hline Desvios & 3 & 0,044 & ns & 1,70 & 0,033 & ns & 0,74 & 0,016 & ns & 1,15 & 0,073 & ns & 3,12 \\
\hline Erro & 20 & 0,070 & & & 0,577 & & & 0,070 & & & 0,577 & & \\
\hline
\end{tabular}

* significativo a 5\% de probabilidade pelo teste $\mathrm{F}$.

eles possuem (CRUZ \& REGAZZI, 1997). Assim, a prevalência de efeitos aditivos no controle genético da resistência à mancha-de-Phaeosphaeria contituise em um indicativo de facilidade na identificação de genótipos superiores, com maior concentração de alelos favoráveis; portanto, uma condição favorável ao melhoramento genético.

A predominância dos efeitos gênicos aditivos na resistência à mancha-de-Phaeosphaeria em milho também foi observada nos trabalhos de LIMA et al. (1998), PATERNIANI (1998), CARSON (2001), PEGORARO et al. (2002) e SILVA (2002). No entanto, os resultados obtidos por DAS et al. (1989a; 1989b) evidenciaram predominância dos efeitos gênicos dominantes, indicando que o controle genético do

Tabela 4 - Resumo da análise de variância conjunta da avaliação da severidade da mancha-de-Phaeosphaeria de seis gerações dos cruzamentos (DAS21xDAS95 e DAS21xDAS72) e porcentagens da variação genética explicada pelos efeitos gênicos aditivos, dominantes e pelo desvio do modelo aditivo dominante nos experimentos. Indianópolis, MG, 2000/2001.

\begin{tabular}{|c|c|c|c|c|c|c|}
\hline \multirow{2}{*}{ Fonte de variação } & \multirow{2}{*}{ GL } & \multicolumn{3}{|c|}{ DAS95 x DAS21 } & \multicolumn{2}{|c|}{ DAS72 x DAS21 } \\
\hline & & $\mathrm{QM}$ & & $\%$ & $\mathrm{QM}$ & $\%$ \\
\hline Total & 12 & & & & & \\
\hline Parâmetros & 6 & & & & & \\
\hline Aditivo (A) & 1 & 17,7435 & $*$ & 72,83 & 8,6896 & * 73,95 \\
\hline Dominante (D) & 1 & 5,0016 & $*$ & 20,52 & 1,5070 & * 12,83 \\
\hline Ambiente (L) & 1 & 0,7407 & $*$ & 3,04 & 1,2826 & * 10,92 \\
\hline$A \times L$ & 1 & 0,6430 & $*$ & 2,63 & 0,2339 & 1,99 \\
\hline $\mathrm{D} \times \mathrm{L}$ & 1 & 0,1127 & & 0,46 & 0,0133 & 0,11 \\
\hline Desvio & 6 & 0,1223 & & 0,50 & 0,0324 & 0,28 \\
\hline Erro & 40 & 0,0641 & & & 0,0641 & \\
\hline
\end{tabular}

* significativo a 5\% de probabilidade pelo teste F. caráter pode variar entre diferentes fontes de resistência, o que deve ser considerado nos programas de melhoramento, que devem caracterizar suas fontes de resistência para que o processo de seleção seja eficiente.

As estimativas da herdabilidade no sentido amplo para resistência à mancha-de-Phaeosphaeria foram altas, de aproximadamente 84 e 75\% nas análises individuais e de $71 \%$ na análise conjunta para o cruzamento DAS95 x DAS21, e de 71 e $61 \%$ nas individuais, e de $63 \%$ na conjunta para o cruzamento DAS21 x DAS972. Essas magnitudes de herdabilidade também foram obtidas por CARSON (2001), com variação de 70 a 85\%, e SILVA(2002), com variação de 63 a $88 \%$.

Os altos valores de herdabilidade e a grande importância do efeito gênico aditivo no controle do caráter são favoráveis ao melhoramento para características controladas por vários genes. Os resultados indicam a existência de dois a três genes ou blocos gênicos segregantes envolvidos no controle genético da resistência à mancha-de-Phaeosphaeria, nos cruzamentos DAS95 x DAS21 e DAS72 x DAS21, respectivamente. CARSON (2001) encontrou de três a quatro genes e SILVA (2002) de um a três. Os números de genes ou blocos gênicos encontrados reforçam as indicações de CARSON (2001) e SILVA (2002) de controle oligogênico na resistência à mancha-dePhaeosphaeria em milho.

\section{CONCLUSÃO}

Os efeitos gênicos aditivos predominam na resistência à mancha-de-Phaeosphaeria e a característica tem alta herdabilidade nas populações estudadas, o que facilita o melhoramento genético. 


\section{AGRADECIMENTOS}

À Fundação de Amparo à Pesquisa do Estado de São Paulo, pelo financiamento dos projetos 99/09170-7 e 01/ 02793-0, e à empresa Sementes DowAgroSciences Ltda, pelo apoio na realização dos experimentos.

\section{REFERÊNCIAS}

AGROCERES. Guia Agroceres de sanidade. São Paulo: Sementes Agroceres, 1996. 72p.

CARSON, M.L. Inheritance of resistance to Phaeosphaeria leaf spot of maize. Plant Disease, v.85, n.7, p.798-800, 2001 .

CASTLE, W.E. An improved method of estimating the number of genetics factors concerned in cases of blending inheritance. Science, v.54, p.223, 1921.

CRUZ, C.D.; REGAZZI, A.J. Modelos biométricos aplicados ao melhoramento genético. Viçosa: UFV, 1997. 390p.

DAS, S.N. et al. Further studies on the inheritance of resistance to Phaeosphaeria leaf spot of maize. Indian Journal Mycology Research, v.27, n.2, p.127-130, 1989a.

DAS, S.N. et al. Inheritance of resistance to Phaeosphaeria leaf spot of maize. Annual Agricultural Research, v.10, n.2, p.182-184, 1989b.

FERNANDES, F.T.; OLIVEIRA, E. Principais doenças na cultura do milho. Sete Lagoas: Embrapa-CNPMS, 1997. 80p.

GOMES, F.P. Curso de estatística experimental. 13.ed. Piracicaba: Nobel, 1990. 468p.

LIMA, M. et al. Cruzamentos parciais entre linhagens de milho com ênfase na produtividade e doenças foliares. In: CONGRESSO NACIONAL DE MILHO E SORGO, 22., 1998, Recife, PE. Anais... Recife: IPA, 1998. v.22, p.38.
LOPES, M.T.G. Mapeamento de genes de resistência à mancha de Phaeosphaeria em milho. 2003. 117f. Tese (Doutorado em Agronomia) - Curso de Pós-graduação em Genética e Melhoramento de Plantas, Escola Superior de Agricultura "Luiz de Queiroz”, Universidade de São Paulo.

MATHER, K.; JINKS, J.L. Biometrical genetics. Ithaca: Cornell University, 1971. 382p.

MIRANDA FILHO, J.B. Quantitative analysis of a cross between populations and their derived generations. Revista Brasileira de Genética, v.14, n.2, p.547-561, 1991.

PATERNIANI, M.E.A.G.Z. et al. Cruzamentos dialélicos entre linhagens de milho com diferentes níveis de resistência a moléstias foliares. In: CONGRESSO NACIONAL DE MILHO E SORGO, 22., 1998, Recife, PE. Anais... Recife: IPA, 1998. v.22, p.98.

PEGORARO, D.G. et al. Herança da resistência à manchafoliar de feosféria em milho. Pesquisa Agropecuária Brasileira, v.37, n.3, p.329-336, 2002.

REGINATO NETO, A. Incorporação de germoplasma exótico de milho (Zea mays L.). 1998. 133f. Tese (Doutorado em Agronomia) - Curso de Pós-graduação em Genética e Melhoramento de Plantas, Escola Superior de Agricultura "Luiz de Queiroz”, Universidade de São Paulo.

REIS, E.M.; CASA, R.T. Manual de identificação de moléstias em milho. Passo Fundo: Aldeia Norte, 1996. 80p.

SILVA, H.P. Genética da resistência à Phaeosphaeria maydis em milho. 2002. 105f. Tese (Doutorado em Genética e Melhoramento de Plantas) - Curso de Pós-graduação em Agronomia, Universidade Estadual de São Paulo.

WRIGHT, S. Systems of mating. the biometric relations between parent and offspring. Genetics, v.6, p.111-178, 1921. 